\title{
Conceptualising Global Strategic Sustainability and Corporate Transformational
}

Change.

\section{Dr Helen Borland}

Birmingham Business School, University of Birmingham, UK.

For correspondence please contact:

Dr Helen Borland

Birmingham Business School,

University of Birmingham,

University House,

Edgbaston Park Road,

Birmingham, UK,

B15 2TT

Phone: 0044 (0) 1214158179

Email: h.m.borland@bham.ac.uk 


\title{
Conceptualising Global Strategic Sustainability and Corporate Transformational Change.
}

\begin{abstract}
Purpose - The purpose of this paper is to present the concept of global 'strategic sustainability', represented by a conceptual framework, the 'Spheres of Strategic Sustainability'. The paper examines routes, solutions, and a vision for corporate strategic sustainability in the macro context of the global physical environment and the planet. This builds on previous research identifying key drivers and strategies for corporate sustainability.
\end{abstract}

Design/methodology/approach - The paper is conceptual in nature and underpinned by Gaia theory, ecosystems theory and the laws of thermodynamics. These three offer specific foci for sustainability research including holism, integration and synthesis: without which, sustainability research would be difficult to achieve.

Findings - The paper identifies two major domains - 'corporate' and 'consumer' strategic sustainability. It examines the corporate domain in which routes are identified through responses to existing globalisation, corporate strategy and corporate culture.

Research limitations/implications - The paper provides insight and preliminary conceptual development towards a full theoretical model of corporate and consumer strategic sustainability. The framework will guide future conceptual and empirical investigations and broaden and deepen our understanding of how firm's can construct strategic business models that incorporate sustainability.

Originality/value - The paper offers a conceptual framework that develops the concept of 'corporate strategic sustainability' and provides positive, practical solutions to incorporating sustainability into business models. It also challenges the current dominant socio-economic paradigm and sets the scene for a more positive eco-paradigm that serves the present and future needs of the planet, environment, businesses and human society.

Key words: Globalisation, Corporate strategy, Organisational change

Article Type: Conceptual Paper 


\section{Introduction}

The purpose of this paper is to introduce the concept, explore routes and offer solutions to global strategic sustainability. Conceptually, strategic sustainability is the integration of the principles of sustainability with corporate strategic management processes, structures, cultures, systems and technologies, enabling both competitive and functional level strategies (Stead and Stead, 2004 and 2008; Parnell, 2008; Shrivastava, 1995). The aim of this paper is to deepen our understanding of the integrated, systems-based and holistic nature that is required in corporate decision-making to create sustainable solutions for the future. Using principles from ecological and environmental sciences, to provide a broad platform (Shrivastava, 1995; Capra, 1997; Ekins, 2000), the author presents a framework that builds on previous research in the area of sustainable strategic management (Hall and Vredenburg, 2003; Stead and Stead, 2004 and 2008; Parnell, 2008; Shrivastava, 1995; McDonough and Braungart, 2002a; Hart, 1997 and 2007; Hart and Milstein, 2003) offering a new capstone framework that uses closed-loop, open systems, circular and eco-effective business models that provide an environmentally sustainable outcome for humans, natural ecosystems and the planet itself. Recognising, accepting and identifying with (Du Nann Winter and Koger, 2004) the interrelationships and interdependencies between all life forms on Earth is the essence of future success and the essence of a new paradigm, identifying with life itself as the central philosophy (Capra, 1997).

In adopting this new paradigm, Hart (1997) suggests that the impact of the organisation on the environment in the future, needs to be positive and if not positive, at worst neutral. This principle applies at local, national, international and global levels and needs to be adopted by all organisations within a given network - manufacturers, suppliers, retailers, distributors and all stakeholders in order for it to work efficiently and effectively (Capra, 1997 and 2004; Hall and Vredenburg, 2003).

This current paper offers a conceptual framework of concentric circles that mirror one another in the corporate and consumer domains. The framework is known as the 'Spheres of Strategic Sustainability'. These 'Spheres of Strategic Sustainability' are presented as a starting point for organisations who wish to take on-board the principles, philosophy, requirements, strategies and 
solutions of sustainability, at a corporate strategic level, in order that they may understand their role more deeply.

\section{Take in Figure 1}

In order to understand how to integrate sustainability into strategic thinking, the author offers below a commentary on some key routes and potential solutions. The significance of other plant and animal species are not discussed specifically, although the author notes and acknowledges that they actually play the essential role in maintaining the balance, homeostasis, and integrity of all life on Earth and thus all global and local natural ecosystems, including human ecosystems. As Judge (2002:9) reminds us:

"We can't make the Earth sustainable; it is sustainable - but whether with us, or without us, is our choice."

Even more poignant, Lovelock (2000a:28) reminds us:

"Gaia theory points to the fact that humankind's environmental sensitivity need not be altruistic. Although environmental debates are often couched in terms of "saving the planet", research results from Gaia theorists make it clear that the planet can take care of itself. What is threatened via ecological and social degradation is not the planet but humankind and its way of life. Thus, achieving sustainability will require balanced, complex interactions involving both co-operation and competition among all of the planet's subsystems, or the human condition will suffer as a result."

Our current way of life and 'quality of life' are clearly under threat but, despite these reminders, there are numerous business opportunities waiting to be taken up by organisations that are willing to be true leaders in identifying and managing new products, services, ideas, and new values, consumer cultures and behaviours. The winners in the new business world will displace and replace existing players who have not made the necessary changes to adapt to the new business or world paradigm; a paradigm that actually holds the potential to improve our current quality of life rather than diminish it (Hart and Milstein, 1999; Hall and Vredenburg, 2003; Lovins, 2007). 


\section{Theoretical positioning}

In much business research, issues to do with the environment and sustainability have been traditionally subsumed within business ethics and/or corporate social responsibility literatures (Daub and Ergenzinger, 2005; Ketola, 2007; Porritt, 2007). However, tangentially, some authors have begun to recognise the fundamental significance of the environment in supporting all human activities and particularly business activity as a separate and important area of consideration (Shrivastava, 1995; Hart and Milstein, 1999; Sharma et al. 1999; Ekins, 2000; Hall and Vredenburg, 2003; Stead and Stead, 2004 and 2008; McDonough and Braungart 2002a; Hart, 1997 and 2007; Hart and Milstein, 2003; Borland, 2009). Indeed, private sector corporate agendas currently abound with sustainability and climate change priorities, projects and practices, as organisations begin to acknowledge more openly their dependence on their exploitation of the Earth's surface and atmosphere.

In this paper, the author focuses on corporations and the role they play in environmental sustainability solutions, as the unit of analysis for the following reasons. First, corporations are the primary engines of economic development. Second, they have financial resources, technological knowledge, and institutional capacity to implement solutions. Third, the examination of environmental sustainability at the organisational level of analysis is both appropriate for the scale of the issues involved and also needs further examination (Shrivastava, 1995; Stead and Stead, 2004). The author also acknowledges that corporations are only one aspect of sustainability. Consumers and governments must also be willing to participate: although, discussion of these two groups is beyond the scope of this current paper.

In positioning this research within the literature, the author adopts the concept of the 'quadruple top line' rather than the 'triple bottom line' (Elkington, 1999).

\section{Take in Figure 2}

When the triple bottom line is adopted, invariably, it is the economic dimension that dominates and the social and environmental dimensions become token afterthoughts or measured against the economic dimension (McDonough and Braungart, 2002a). McDonough and Braungart (2002b) 
suggest a 'triple top line' approach that improves the balance of the three, yet, the balance of the equation still favours humanity with two (economic and social) dimensions versus one environmental dimension. In fact, socio-cultural well-being is usually dependent on economic (financial) well-being. In the same vein, environmental well-being is dependent on the physical well-being of the planet itself, the Gaia Principle, and therefore environment and planet need to be considered separately. In considering them separately, the four dimensions need to be financially accounted for separately, so that the environmental and planetary dimensions receive equal consideration and are perceived with equal importance. In this way, the significance of the relationships and the interdependencies of the living and non-living elements of the biosphere will be recognised (Capra, 1997), and extractive industry as well as the harvesting of living material will need to be shown on the quadruple balance sheet.

In fact, in proposing a quadruple top line, the author sees a hierarchy of dimensions developing:

\section{Take in Figure 3}

This hierarchy emphasises the underlying importance of the planet and the environment in sustaining and maintaining all life on Earth and in providing the richness and diversity of financial and sociocultural benefits that we enjoy (Naess, 1988 and 1995; Capra, 1997; Hart and Milstein, 1999). Developing this perspective, our lives would be diverted away from our current anthropocentric (Dunlap et al. 2000; Capra 2004) and narcissistic (Du Nann Winter and Koger, 2004) existence, towards a more eco-centric and ecologically deep existence (Naess, 1988 and 1995; Sessions, 1995; Capra, 1997). This would, undoubtedly, save us all a great deal of anguish, but achieving this level of collective understanding and transformation will be difficult (Du Nann Winter and Koger, 2004) and, in fact, to achieve this requires understanding and education (Kilbourne and Carlson, 2008) at the socio-cultural level, indicated by the feedback loop in Figure 3.

From this perspective, the underlying planetary and environmental dimensions become the basis for sustainability definitions (as provided by Judge (2002) and Lovelock (2000a) in the Introduction) 
rather than the currently acknowledged, and more limited existing anthropocentric definitions, such as the one provided by the Brundtland Commission Report in 1987:

"Meeting the needs of the present without compromising the ability of future generations to meet their needs."

A further step in conceptual thought posits that if sustainability is about the balance of nature, people and the planet; about accepting that humans are just one species amongst many; that all natural resources, including water, are finite and precious; and that accepting that with so many humans living on Earth, we will need to plan for the future of our own survival. The next question then becomes how do we plan for our, and for other species' future survival on Earth? It is this need to plan and to strategise that gives rise to the concept of 'strategic sustainability' (Borland, 2009).

Strategic sustainability, thus, incorporates four essential elements omitted from previous definitions: it acknowledges that the base point for a definition of sustainability is the planet's natural systems, integration and homeostasis; that living beyond the balance of natural systems is not sustainable; that all resources, both renewable and non-renewable, are finite and precious; that all living species need to be included otherwise ecosystems will eventually collapse.

Therefore, strategic sustainability becomes: an activity of planning for the future of our own and other species' survival; recognising the need for an 'individual, collective and cultural transformation and paradigm shift'; understanding the part that humans play, in all walks of life, in creating a sustainable human future in corporate, consumer and government activity in all parts of the World; understanding how theories, models and concepts of business, marketing and our wider life will be different when they include sustainability: for example, closed-loop, systems-based, integrative, eco-effective models that incorporate the full life-cycle, rather than the existing linear, cradle to grave theories and models currently in use.

A number of sustainability concepts have been developed including Hart (1997 and 2007); McDonough and Braungart (2002a); Hart and Milstein (2003); Stead and Stead (2004); Borland (2009). Each makes a positive contribution to Strategic Sustainability yet alone no one model 
provides the ultimate answer. By drawing them together, using principles from sustainability (Capra, 2004), they help to create a solution and vision of corporate strategic sustainability for organisations both large and small, in any part of the world. Solutions that will enable companies to eliminate waste from their industrial manufacturing processes, and from consumer end-of-life processes, to cut the use of virgin raw materials, to improve water and air quality, to provide a sustainability vision, values and strategy, and potentially save money.

This paper continues by reviewing some of the underlying scientific principles of the environment, namely Gaia Theory, the Laws of Thermodynamics and Ecosystems Theory. It then examines three areas of corporate activity that have been identified as possible routes for incorporating corporate sustainability - globalisation, corporate strategy and corporate culture. It then examines some of the existing sustainable business models, and builds a new systems-based, integrated, holistic, conceptual framework for Strategic Sustainability. Finally, the paper discusses the paradigm shift that is inherent in the approach being proposed and outlines some significant implications of the current research.

\section{Environmental science theory - background and literature}

Gaia theory; the laws of thermodynamics and ecosystems theory

The starting point for discussion regarding environmental sustainability, and how companies can operate sustainably, needs to begin with an appreciation of some of the key scientific principles that govern the global environment. Gaia Theory, the Laws of Thermodynamics and Ecosystems Theory explain each in turn, how both animate and inanimate components, which make up the Earth's surface and its atmosphere, behave. Gaia Theory is a complex concept that has at its core the interrelationships between the physical, chemical and biological elements of life on Earth (Lovelock, 2000b). The essence of this concept is that, it is life on Earth that creates and regulates the atmosphere and therefore regulates its own existence, which creates a state of homeostasis (a complex balance of all living and non-living things). Gaia does not provide preferential treatment to any particular species or any particular part of the globe. Gaia represents holism, diversity, complexity, 
constancy, consistency, quality of life, cooperation and competition: instrumental values that can also be reflected by modern corporations, pursuing a core value of sustainability. Reductionist research does not sit well with Gaia for the same reasons that it does not benefit organisations interrelationships between activities and objects cannot be measured or monitored (Capra, 2004; Lovelock, 2006). Lovelock (2000b: 19) describes Gaia thus:

"....the atmosphere, the oceans, the climate, and the crust of the Earth are regulated at a state comfortable for life because of the behaviour of living organisms. Specifically, the Gaia hypothesis says that the temperature, oxidation state, acidity, and certain aspects of the rocks and waters are at any time kept constant, and that this homeostasis is maintained by active feedback processes operated automatically and unconsciously by the biota. Solar energy sustains comfortable conditions for life. The conditions are only constant in the short term and evolve in synchrony with the changing needs of the biota as it evolves. Life and its environment are so closely coupled that evolution concerns Gaia, not organisms or the environment taken separately."

In envisioning Gaia, it helps to relate the health of the planet to the health of a human being. Humans also have a homeostatic balance. When our body temperature rises because we are unwell, our body works hard to bring our temperature back down and to regain the temperature balance. In a similar way, when something is out of balance with the planet, nature works hard to bring it back into balance for the benefit of its inhabitants. As nature, as a whole, is more powerful than human society, it makes eminent sense for companies, and individuals, to learn how they can work with nature rather than against it, if they wish to benefit long-term (Capra, 2004).

The Laws of Thermodynamics are the second principle under consideration. There are two laws, the first law, the conservation law, states that the amount of energy released by the big bang is a constant in the universe. Energy cannot be created nor destroyed; it can only be transformed from one state to another. The amount of energy generated during this transformation depends on the temperature difference between the states (hence the term "thermodynamics"). The second law of thermodynamics says that every time energy is transformed from one state to another, some of its 
available energy to do work is lost. This process is called "entropy". Entropy occurs when stored energy becomes cooler, less concentrated, or less ordered when it is applied to do work. When energy is no longer available to do work, when it has degraded to the point of being useless, it becomes waste (Stead and Stead, 2004). The entropy law, thus, dictates that all things have a tendency to go from a higher state to a lower state, from a higher level of energy to a lower level of energy, or put another way, from order to chaos (Capra, 2004). We can see this for ourselves, for example, when an iron bar is left out in the rain; it decomposes to ferrous oxide (red and crumbly) and eventually rusts away. The energy is released and its usefulness, to humans, is lost.

The laws of thermodynamics are central to the sustainability debate. Firstly, the amount of energy in the environment is constant; it cannot be created or destroyed. Secondly, during the entropy process, energy tends to go from a higher order state to a lower order state when we apply it to do work and thus is lost in terms of human usefulness, but is not lost from the environment. Humans are notoriously inefficient at converting energy and most of the energy we exploit is lost to the atmosphere, ground, waterways or landfill sites; take, for example, petrol cars, most of the energy from the fuel is lost to the atmosphere along with noxious gases (Du Nann Winter and Koger, 2004).

The third concept is (Eco)Systems Theory. Systems theory has as its central tenet, the principle that life's systems are non-linear (Checkland, 1999; Skyttner, 2006). However, existing business and economic models depict linear processes, relationships and systems (Porter and van der Linde, 1995; Porter, 2008; Capra, 2004). There is an immediate and obvious conflict here when trying to predict the outcome of certain business activities in a physical environment that works cyclically and nonlinearly.

Given the principles of Gaia Theory and the Laws of Thermodynamics, it is not surprising to note that planet Earth is a 'closed system' (Kitching, 1983; Odum, 1994). This means that the energy and matter contained on and in the Earth are constant and finite and therefore non-renewable. Technically speaking, they are renewable but they need specific conditions and a very long period of time to renew and therefore in terms of human usefulness, they are non-renewable. The only exception to the 
closed system rule is the input of sunlight. Sunlight is a renewable energy source, at this current time, and is available across the globe (Naess, 1988). It is the most important source of renewable energy and is freely available; the significance of this fact is enormous. With non-renewable resources being finite and limited, renewable resources (sunlight and thus, wind, wave, and all types of flora) are the only replaceable energy sources. It also so happens that sunlight and flora form the basis of all life on Earth - they provide us with the food we eat. Therefore, from sunlight natural ecosystems are created (Sessions, 1995). A natural ecosystem follows the principles of systems theory in that it is non-linear, and is also the basic environmental 'unit of analysis'. From this unit of analysis, energy generation, utilisation and consumption can be measured in much the same way as they can within an organisation (Odum, 1994). Ecosystems support life in a unique, complex and diverse system of interrelationships and interdependencies. Ecosystems can overlap each other with animal species travelling between different local ecosystems. The conglomeration of the different natural ecosystems gives rise to the 'global ecosystem' a complicated patchwork of highly intricate and complex living relationships that form a perfectly, synchronised system supporting all known life forms (Lovelock, 2000a; Kitching, 1983; Odum, 1994).

\section{Conceptual development - the routes to strategic sustainability}

There are a number of relevant implications that arise from observing Gaia, Thermodynamics and Ecosystems theories. The first is that the human race is not regarded as a special case: we are subject to the same laws on Earth as all other species. The second is that because we live in a closed system, most natural resources are limited and finite. Yet, our use of them is increasing exponentially as our population increases exponentially and our per capita GDP also increases significantly (Capra, 1997; Ekins, 2000). The third implication of living in a closed system is the waste and pollution issue (high entropy material). One of the goals for human societies, and particularly organisations, must be to create effective use of energy and matter (goods and materials), and to reduce waste in all known processes, because there is no extra-terrestrial rubbish bin for us all to deposit our waste in. 
In developing a framework for Strategic Sustainability, the author needs to incorporate the lessons that Gaia, Thermodynamics and Ecosystems theories provide. The outer circles of the framework (Figure 1) encapsulate the six key drivers that provide the impetus for developing a strategic sustainability approach (Borland, 2009). The second (middle) circles of Figure 1 illustrate potential routes for incorporating the needs of businesses and human society with the physical environment and planet; at this point, the corporate and consumer domains separate from one another as different routes are identified; one leading to 'Corporate Strategic Sustainability' and the other leading to 'Consumer Strategic Sustainability'. These two routes do, however, reflect and mirror one another creating conceptual constructs for future potential consideration and measurement, for example:

\author{
Globalisation $\leftrightarrow$ Localisation \\ Corporate Strategy $\leftrightarrow$ Consumer Education \\ Corporate Culture $\leftrightarrow$ Consumer Culture
}

The following discussion focuses on 'Corporate Strategic Sustainability' with each of the three components above being considered briefly. Limitations on space prevent a more detailed discussion of the relationship between them; although, hopefully, future analysis and debate on the routes to Strategic Sustainability will be encouraged by this commentary. The author begins with the part played by globalisation.

\title{
Routes to corporate strategic sustainability
}

\section{Globalisation}

In the corporate domain, globalisation has a significant part to play (Viswanathan and Dickson, 2007). The global reach of some corporations today is unprecedented in human history, in terms of both their influence on consumers and governments, and their impact on the environment. Coupled with this is the global reach of certain environmental problems (Porritt, 2007). Many environmental problems by 
their very nature are 'global', such as global warming and the melting polar ice caps (Shrivastava, 1995). For others, actions conducted in one part of the world affect the physical conditions felt by the occupants of another. (Capra, 2004). Hart (1997) suggests that three world economies exist - the market economy, the survival economy and nature's economy. He argues that although the market economy (in developed and some emerging economies) is improving its physical environment in terms of reduced pollution and reduced natural resource usage, much of the most polluting activities, such as commodity processing and heavy manufacturing, are being relocated to the emerging market economies. Thus, to some extent, the 'greening' of the developed world has been at the expense of the physical environments in emerging economies. Given the much larger population base in these countries, their rapid industrialisation could easily offset the environmental gains made by developed economies. This lack of a 'holistic' vision seen by many 'global' companies (and governments) is referred to by Senge (2006) as 'organisational learning disability'. Thomas (2008) describes it as the failure of organisations to understand their 'holistic' role. Their 'dogged' pursuit of the financial bottom line and a focus on shareholder value has led them to ignore the wider implications of the role of the corporate entity in society [and the environment] (Thomas, 2008).

Klein (2000) suggests that global corporations 'are much more than the purveyors of the products we all want; they are also the most powerful political forces of our time, the driving forces behind bodies such as the World Trade Organisation'.

With global reach and political influence, large corporations are a suitable vehicle for initiating a 'holistic' strategic sustainability approach (Porritt, 2007). Thus, with comparable changes to corporate strategy and corporate culture (and paralleled changes in consumer culture) strategic sustainability can be initiated.

\section{Corporate Strategy}

Visions, missions, values, objectives and strategies are the traditional responsibility of corporate strategy, providing companies with a 'personality' and style of doing things (Hatch and Schultz, 
2001). This strategic 'guiding hand' extends to the functional operational levels to instil purpose, direction and corporate goals (Capra, 2004). However, in recent years, these goals have become myopic, as Thomas (2008) reports above, focused heavily on the financial bottom line and shareholder value; rather than the wider philanthropic gestures, or corporate social responsibility, exemplified by some of our corporate ancestors (Aguilera, Rupp, Williams and Ganapathi, 2007; Campbell, 2007; Porritt, 2007).

Corporate strategy is part of the vehicle for strategic sustainability on a global scale. Organisations looking for a special competitive advantage, in our post-industrial era, who are also in search of a wider sense of purpose and a more 'holistic' or spiritual sense of being, will question their impact on the natural and human environments (Sharma and Vredenburg, 1998). Stead and Stead (2004) have proposed eight instrumental corporate values to guide companies who have a core value of sustainability. These eight instrumental values are: wholeness, posterity, community, appropriate scale, diversity, quality, dialogue and spiritual fulfilment. To this list, the current author adds: holism, homeostasis, circular flows, ecosystems, synthesis, transformation, diversity, complexity, quality of life, co-operation and competition. As expected, there is a noticeable cross-over between the two.

Sustainability values do not need to compromise financial success, instead, they can broaden the base and enhance opportunities for further success (Porritt, 2007). The current dominant 'socio-economic paradigm' only considers financial measures of success (Capra, 2004; Kilbourne, 2004). However, strategic sustainability incorporates the 'Quadruple Top Line' approach with measures of planetary (earth), environmental (ecological), financial (economic) and social (equity) success. Broadening the base in this way allows companies to look beyond their traditional financial bottom line at other routes to financial and non-financial success for the organisation. In many cases, this also provides enhanced financial gains too, for example, Marks and Spencer's recent change in corporate strategy and direction ('Plan A'), has created additional financial benefits.

However, shifting the financial parameters in this way also initiates other internal and external shifts (Sharma and Vredenburg, 1998). The current dominant socio-economic paradigm to which we all 
subscribe (Kilbourne, 2004) is making way for a fundamentally new paradigm or worldview which subscribes to a more holistic way of life that recognises the interconnections, interdependencies and inter-relationships of the natural and human environments (Shrivastava, 1995). It recognises that business does not operate in a vacuum, that it, too, is a part of this larger, greater system that is circular in nature rather than linear, and is therefore subject to the same scientific principles (Capra, 2004). Some commentators suggest that this awareness and shift has already begun (Hart and Milstein, 1999; McDonough and Braungart, 2002a; Hart, 1997 and 2007; Prahalad and Hart, 2002; Stead and Stead, 2004 and 2008; Capra, 2004; Porritt, 2007).

Strong leadership is a special requirement of strategically sustainable corporate strategy, particularly from CEOs. Top management support, guidance and involvement in implementing strategic sustainability are crucial. Stead and Stead (2004) suggest that 'CEO's are the primary change agents responsible for instituting a strategic sustainability approach in their organisations and, collectively, they are the change agents most responsible for leading the paradigm shift from a closed circular-flow economy to an open living-system economy. They also consider that fulfilling these generative change agent roles will require that strategic sustainability managers be effective leaders, who are able to mould sustainability-centred organisational cultures and structures, to meet the needs of the Earth's stakeholders, to instil spiritual as well as emotional and intellectual intelligence into the learning processes of their organisations. This process is referred to as capabilities for higher-order learning by Sharma and Vredenburg (1998).

From this leadership, other corporate mechanisms are necessary to create change, these include the integration of corporate cultures, structures, human resource management systems, technology, accounting systems, research and development and marketing amongst others.

\section{Corporate Culture}

The culture and, therefore, the values of a company are generated and influenced by the people who make up the company (Hatch and Schultz, 2001). Corporate culture is, generally, initiated by senior 
management but, in large organisations, can be changed and altered more locally by individuals or circumstances (Moss Kanter, 2008). Schumacher (1989) suggested that smaller operating units within companies are good, as large bureaucracies inhibit freedom, creativity, human dignity and damage the ecosystem, and that the only way to reverse the negative effects of vast organisations is to "achieve smallness within large organisations". Human resource (HR) individuals and departments have a key part to play here in instilling certain values, beliefs, assumptions and principles. Changing corporate values, beliefs, assumptions and principles to fit with strategic sustainability are essential for successful implementation. An organisation that is clear in what it stands for internally, will have a far more positive effect on those that it interacts with externally. In particular, fostering a sustainability-centred company culture can influence the attitudes and behaviour of organisational stakeholders over time. It is hoped that helping stakeholders to become more sustainability orientated will lead to greater and deeper levels of strategic sustainability culture both in the company and throughout its influence network (Sharma and Vredenburg, 1998). Regarding the latter, Stead and Stead (2004) report that:

"........ one of the ancillary benefits of creating sustainability cultures is the potential to influence the wider societal culture, especially for companies that have the size, clout or standing to take an effective leadership position" (Stead and Stead, 2004: 177).

HR departments are responsible for providing training and development for employees. Because of the complexity and range of sustainability issues, training and development must go beyond awareness training for many employees (Porritt, 2007). Senge (2006) comments that "learning persons seeking personal visions are the spiritual foundation of the learning organisation". This speaks volumes about the critical role of human resource management in successfully implementing strategic sustainability. One of the prerequisites for a paradigm shift to strategic sustainability is to view employees as having both instrumental and intrinsic value, rather than as liabilities (Drucker, 2002). Simply stated, without qualified, motivated, dedicated, well-trained, and well-led employees, strategic sustainability will not succeed. A number of authors (Daily and Huang, 2002; Egri and 
Hornal, 2002; and Willard, 2002) have delved into human resource requirements, practices, processes and programmes related to corporate sustainability implementation.

Thomas (2008) summarises the requirements of future managers in carrying out their role within organisations as 'Social Trustee Civic Professionals' who take a completely holistic approach to their work, in their respective department: integrating the needs of the firm with those of civic society and the wider physical environment. He suggests that, in the interests of our collective future, it is time to end the consumer market-driven 'pathologies' that currently power our global, engine-economy, companies, and develop a more professionally responsible business paradigm that will ensure we all have a sustainable future on planet Earth.

\section{Bringing it altogether - achieving corporate strategic sustainability}

The purpose of this section is to draw upon some of the existing corporate sustainability concepts, and to use the corporate activities of globalisation, corporate strategy and corporate culture, outlined above, as a conduit for change. To begin with, the author conceded that corporate and consumer Strategic Sustainability (Figure 1, inner circles) may be different, but latterly realised that, in fact, at this point in the conceptualisation, the two need to be reunited in order to discuss them effectively. Corporate and consumer strategic sustainability are the two ends of the same spectrum, again a conceptual construct. Corporate activity is designed to please (rather than satisfy) the consumer and consumer purchasing activity supports corporate existence. Therefore, to discuss one without the other is not realistic.

True Strategic Sustainability requires vision, leadership and commitment. Strategic Sustainability will also work most effectively at an 'industry' level first, and then at the individual company level (Hart and Milstein, 1999). This will create an ethos of cooperation and equitability across competing firms that may be necessary for future industry survival (Shrivastava, 1995). In particular, the work of McDonough and Braungart (2002a); Stead and Stead (2004 and 2008) Hart (1997 and 2007); Hart and Milstein, 2003; and Borland (2009) contributed to the development of the Strategic Sustainability 
framework. Their approaches are quite different from one another, yet, when brought together as a strategic approach, there is a logic and flow that makes strategic sense.

McDonough and Braungart (2002a) realised that the main issue for corporate sustainability was a question of the design of physical products, of all kinds. Many everyday household products give off levels of noxious and dangerous substances and industry disposes of vast amounts of dangerous substances into the environment daily. These substances are crippling the environment and also crippling human health. They turned to 'intelligent design' as opposed to 'unintelligent design', to solve the issues and concluded that 'industrial ecosystems' need to follow the 'intelligent designs' offered by nature that enhance and add to their local environment rather than the current industrial systems that poison the environment and human health. Their simple mantra 'Waste Equals Food' illustrates the need for product conception, development, manufacture, use and disposal to follow circular, closed loop flows to prevent pollution and waste.

Using the term 'eco-effectiveness', McDonough and Braungart (2002a) suggest that all products should be designed in the future to be made from only two types of materials: 'biological nutrients' and 'technical nutrients'. Biological nutrients are materials that biodegrade and can be returned to the biological cycle without causing any damage to it. Technical nutrients are materials that do not biodegrade but can be circulated continuously through the industrial cycle, thus eliminating waste and pollution, and reducing virgin resource use. This, the authors suggest, provides a more positive outlook for the future of humankind and will allow humans to continue with their current 'lifestyles' and 'quality of life' without the 'guilt trip'.

McDonough and Braungart (2002a) provide a 'cradle to cradle' approach to product design strategy and corporate vision, rather than the traditional negative 'cradle to grave' approach. However, they also, inadvertently, offer a solution to managing supply chains using a conventional, Porter-style value-chain analysis. Stead and Stead (2004 and 2008) emphasise three value chain models, type I, type II and type III. 
It is type III that is of most interest to the concept of strategic sustainability. Type III depicts a closedloop value chain (in an open living system economy) in which there is no waste or pollution. Using only biological nutrients, renewable energy sources and technical nutrients in industrial systems, it produces only safe biological wastes that are reabsorbed into the biological system. However, a supply chain that uses only biological and/or technical nutrients will need to change its manufacturing technology and processes, thus clean technologies will need to be developed (Hart, 1997; Hart and Milstein, 2003).

The transition to managing firms in this type of system will not be easy and major research, development and large-scale investment will be required. Government support for successful transition will be essential, coupled with industry level collaboration. However, given our current global economic predicament, the turbulent nature of the major industrial economies and the exponential growth of the human population in the emerging economies, it seems that this may be the route out of our economic and environmental troubles in a more positive and life enhancing way than has so far been put forward.

In bringing together the contributions of McDonough and Braungart (2002a), with those of Stead and Stead (2004), the author now adds the contribution of Hart (1997 and 2007) and Hart and Milstein (2003). Hart (1997) and Hart and Milstein (2003) offer a portfolio approach to Strategic Sustainability: the 'Sustainability Portfolio'. This portfolio offers companies a 'roadmap' or vision for sustainable change through four stages: Pollution Prevention, Product Stewardship, Clean Technologies and Sustainable Vision.

The stages are progressive and offer greater challenge to the company as they progress towards a sustainability vision. Pollution prevention and clean technologies affect, to a greater extent, the internal operation of the company. Product stewardship and sustainable vision also engage the external elements of the company such as suppliers, customers and other stakeholders.

Although pollution prevention is 'only' the first stage of the process when applying it at a practical level, one needs to consider just how difficult this may be to implement. This first step is not 
'pollution reduction' - a transitional step that many companies are currently trying to achieve, through eco-efficiency, but actual pollution elimination - quite a different demand on the company. Therefore, appearing anywhere in the portfolio is a demanding task for a company and aligns well with McDonough and Braungart's (2002a) eco-effectiveness, and Stead and Stead's (2004) type III value chain.

Interestingly, the 'sustainability vision' discussed by Hart (1997 and 2007) is not that of ecoeffectiveness and type III value chains but that of 'the base of the pyramid', catering to the 4 billion or so poorest people in the world who are currently outside of the capitalist economy (Prahalad and Hart, 2002). Whilst this is viewed as a noble objective, it may not achieve the sustainable future its authors originally envisioned.

However, in bringing together the three approaches, and adding the contribution of the conceptual framework, underpinned by environmental science theory, the author puts forward a Strategic Sustainability concept and vision that incorporates the redesign of products (and services) using only biological and technical nutrients as components and materials for finished products. That then enables the supply chain, from source to consumer, and beyond, to become a 'closed-loop' system that does not leak or leach unwanted and dangerous substances into the environment, and that closes the waste loop, making the transfer of nutrients a continuous process from cradle to cradle (Type III). Addressing Hart's (1997and 2007) sustainability portfolio matrix, one can then observe that the type III, cradle to cradle approach, would succeed in achieving pollution prevention; and product stewardship; it would also require clean technologies to be developed; and finally, would also provide a clear and unambiguous sustainability vision that would be applicable and implementable in the developed nations, the emerging economies, the developing nations and also in the 'base of the pyramid' societies around the world.

The conceptual framework put forward in this paper thus offers a capstone conceptual model that brings together the drivers, routes to strategic sustainability and also a strategic vision or solution that will create a successful strategic sustainability approach. It incorporates some existing corporate 
sustainability models, and synthesises them into a holistic vision and 'route map' for Corporate Strategic Sustainability.

This paper, in the true spirit of sustainability, and unlike conventional academic research, holds true to the principles of synthesis rather than analysis, holism rather than reductionism and integration rather than separation (McDonough and Braungart, 2002a; Capra, 2004). In so doing, the author offers here the 'Spheres of Strategic Sustainability' as a conceptual model, that builds on previous research and also builds on the author's conceptualisation of the 'quadruple top line' and 'hierarchy of strategic sustainability'. It also encapsulates and incorporates the major elements of the sustainability debate; its scientific principles, its drivers, its routes to corporate change and a strategic sustainability vision for the future. The known weakness of the conceptual model is that it does not illustrate the time dimension that is inherent in any sustainability solution and time is the one thing we have very little of, if we are to create an effective change.

\section{A corporate strategic sustainability paradigm shift}

It is important to recognise that in putting forward such a radical proposal for change the author is, in fact, creating a suggestion for a fundamental paradigm shift away from the way global industry currently operates, and consumers consume.

Currently, global industrial society lives within a paradigm that stems from the $17^{\text {th }}$ century (Locke, 1980) and is thus nearly four hundred years old. This paradigm, variously known as the dominant social paradigm, the economic paradigm or the socio-economic paradigm, is born out of the idea of 'possessive individualism' in which individuals are regarded as atomistic and in possession of themselves rather than subservient to a higher authority. This ideology gave rise to private property rights and the accumulation of land and material possessions as a virtue rather than a vice, as had been the previous ecclesiastical notion. It was regarded as the birth of the capitalist ideology but also led to the removal of nature, the environment and ethics from economic enquiry (Kilbourne, 2004). 
Cotgrove (1982) stated that a paradigm is not dominant because it is held by the majority but because it is held by dominant groups who use it to legitimise prevailing institutions supporting their interests. Thus, the paradigm's guiding principles become self-evident to members of the community and require no justification. When anomalies appear within the paradigm, adherents reconcile them within the paradigm by using the prevailing form of rationality that is also determined by the paradigm. For the Dominant Social Paradigm (DSP) of industrial societies, this is technological rationality (Habermas, 1989; Marcuse, 1964) because it is also consistent with the production of material wealth and the accumulation of capital.

Cotgrove (1982), therefore, describes a self-perpetuating situation in which the economy of 'unlimited' economic growth supports itself and supports the proponents of it, those who want to gain more and more economic wealth and power. It becomes self supporting, self-justifying, and selfprophesying (Porritt, 2007). However, it is predicated on the concept of unlimited economic growth which requires that no one can become better off at the expense of someone else. This is based on absolute gains rather than relative gains. But the only way this can happen consistently without political intervention, is under conditions of continuous economic growth. With growth, accumulation of capital is unabated so long as it comes from the marginal increase and not from someone else's existing share of the pie. This justifies the limitless increases of some because others have not been made worse off absolutely. Again, this is in the immediate interest of capital.

The four hundred year old paradigm of economic and political liberalism is becoming dated as economists, accountants, scientists, academics and others begin to realise that the natural base on which this wealth has, traditionally, been created is, in fact, limited and fragile, and is at the expense of the human poor, the physical environment and the planet (which is indirectly at the expense of each of us) (Hart and Milstein, 1999). The concept is further marred by exponentially increasing human populations all clambering for further economic wealth and development (Capra, 2004). Technology does not appear to be keeping pace with consumption patterns, pollution, waste and resource utilisation (Lovelock, 2006) or is it the political will of governments and industry that is not allowing 
the new technology to take its place in society quickly enough and freely enough, for fear of damaging the existing economic paradigm?

The future is bright for human society but it will require engagement from those that hold the keys to the current 'economic paradigm' (governments, NGO's, religions and global companies) to allow change to take place, to allow a 'transformation' and a 'paradigm shift' in the way we value ourselves, animals, plant life, the environment and the planet itself. Changing human values to a core value of 'sustainability' with instrumental values of wholeness, posterity, community, appropriate scale, diversity, quality, dialogue and spiritual fulfilment as outlined by Stead and Stead (2004), will require a fundamental rethink by governments, industry, religious leaders and economists, and a commitment to saving ourselves and saving the future of our 'quality of life' on planet Earth along with that of the ten million or so other species that we currently share this planet with. Holism, homeostasis, circular flows, ecosystems, synthesis, transformation, diversity, complexity, quality of life, co-operation and competition will become the buzz words of the new eco-paradigm and they are the cornerstones of corporate strategic sustainability as outlined in this current paper.

A new paradigm may allow us to let go of the old property, land and material accumulation paradigm (exponential population growth may force us to let go); or alternatively, allow us to hang on to it but without utilising and wasting so much of the Earth's natural resources, or possibly utilising a completely different set of resources. Whatever shape the future takes, it will have to be different from the current paradigm and it will need to involve a transformation, a paradigm shift and a new set of beliefs and values.

As Albert Einstein famously observed:

"If we are to solve the problems that plague us, our thinking must evolve beyond the level we were using when we created those problems in the first place."

(in McDonough and Braungart, 2002a: 165). 


\section{Conclusions and research implications}

This paper is conceptual and theoretical in nature. Building on previous research, it introduces the concept of 'Strategic Sustainability' and presents a conceptual framework: the 'Spheres of Strategic Sustainability'. This research also introduces the 'quadruple top line' and 'strategic sustainability hierarchy' as a means of representing a global or planetary base for research into corporate strategic sustainability. Research from the environmental sciences, namely, ecosystems theory, the laws of thermodynamics and Gaia theory, provides the underpinning for the conceptual developments and teaches us that living in synchrony with the systems of the natural world is, long term, in our interests. The outcome of this research is a proposition for a 'corporate strategic sustainability' approach that embraces previous contributions and builds an integrated, systems-based, holistic and visionary framework for companies to utilise in pursuing sustainability strategies. The next stage of research will need to pursue empirical and financial validation of the proposed frameworks.

Research implications can be lodged at several levels - theoretical, managerial, policy and educational. Most significantly, this paper has tried to convey the importance of having a clear understanding of the scientific base on which we need to examine all our sustainability issues. Without this understanding and knowledge, our attempts and aspirations for creating a more sustainable economy and society will not amount to much. This implication impacts on corporate policy, education policy, government policy and research policy. The second most important implication to develop from this paper is that instead of continuing to focus on our societal sustainability problems, it is time for us to know and acknowledge these problems and attempt to plan, and to 'strategise' our way forward. This paper has attempted to focus on a way forward, exploring positive avenues, solutions and visions for companies who want to implement a positive sustainability approach and be a part of the solution rather than a part of the problem. This positive approach is also applicable to local, national and international government bodies, to education, to research, and to individuals and groups of consumers. Finally, this research illustrates that life's natural systems are circular and cyclical. Our linear patterns of production, consumption, waste disposal and resource usage are not currently synchronised with nature's patterns of production, 
consumption, waste disposal and resource usage. Developing synchronisation and integration will be a major step forward in our strategy for future success.

\section{References}

Aguilera, R., Rupp, D., Williams, C. and Ganapathi, J. (2007), "Putting the S Back in Corporate Social Responsibility: A Multilevel Theory of Social Change in Organisations", Academy of Management Review, Vol. 32, pp. 836-863.

Borland, H. (2009), "Definitions, Theories, Drivers and Managerial Implications: Grounding Global Strategic Sustainability”, Academy of Marketing Science Conference, May, Baltimore, USA.

Brundtland Commission Report, (1987), "The World Commission on Environment and Development”, Our Common Future, Oxford University Press, New York.

Campbell, J. (2007), "Why Would Corporations Behave in Socially Responsible Ways? An Institutional Theory of Corporate Social Responsibility", Academy of Management Review, Vol. 32, pp. 946-967.

Capra, F. (1997), The Web of Life: A New Scientific Understanding of Living Systems, Anchor Books, New York.

Capra, F. (2004), The Hidden Connections: A Science for Sustainable Living, Anchor Books, New York.

Checkland, P. (1999), Systems Thinking, Systems Practice: A Thirty Year Retrospective, J. Wiley and Sons Ltd., Chichester, UK.

Cotgrove, S. (1982), Catastrophe or Cornucopia: The Environment, Politics and the Future, Wiley, New York. 
Daily, G. and Huang, L. (2002), "Achieving Sustainability through Attention to Human Resource Factors" in Sharma, S. and Starik, M. (Eds.), Research in Corporate Sustainability: The Evolving Theory and Practice of Organisations in the Natural Environment, Elgar, Northampton, MA, USA.

Daub, C. and Ergenzinger, R. (2005), "Enabling Sustainable Management through a New Multidisciplinary Concept of Customer Satisfaction”, European Journal of Marketing, Vol. 39, No. 9/10, pp. 998-1012.

Drucker, P. (2002), “They’re Not Employees, They're People”, Harvard Business Review, February, pp. 71-77.

Du Nann Winter, D. and Koger, S. (2004), The Psychology of Environmental Problems, $2^{\text {nd }}$ Edition, Lawrence Erlbaum Associates/Eurospan (London), Mahwah, New Jersey, USA.

Dunlap, R., Van Liere, K., Mertig, A. and Jones, R. (2000), "New Trends in Measuring Environmental Attitudes: Measuring Endorsement of the New Ecological Paradigm: A Revised NEP Scale". Journal of Social Issues, Vol. 56, Fall, pp. 425-442.

Egri, C. and Hornal, R. (2002), "Strategic Environmental Human Resource Management and Organisational Performance: An Exploratory Study of the Canadian Manufacturing Sector”, in Sharma, S. and Starik, M. (Eds.), Research in Corporate Sustainability: The Evolving Theory and Practice of Organisations in the Natural Environment, Elgar, Northampton, MA, USA.

Ekins, P. (2000), Economic Growth and Environmental Sustainability, Routledge, London.

Elkington, J. (1999), Cannibals with Forks: The Triple Bottom Line of the $21^{\text {st }}$ Century, Capstone Publishing Ltd, Oxford.

Habermas, J. (1989), The Structural Transformation of the Public Sphere, Heinemann Educational, London. 
Hall, J. and Vredenburg, H. (2003), “The Challenges of Innovating for Sustainable Development", MIT Sloan Management Review, Fall, Vol. 45, No. 1, pp. 61-68.

Hart, S. (1997), "Beyond Greening: Strategies for a Sustainable World", Harvard Business Review, Vol. 75, No. 1, pp. 66-76.

Hart, S. (2007), Capitalism at the Crossroads, $2^{\text {nd }}$ Edition, Wharton School Publishing/Pearson, New Jersey, USA.

Hart, S. and Milstein, M. (1999), "Global Sustainability and the Creative Destruction of Industries", MIT Sloan Management Review, Fall, Vol. 41, No. 1, pp. 23-34.

Hart, S. and Milstein, M. (2003), "Creating Sustainable Value", Academy of Management Executive, Vol. 17, No. 2, pp. 56-67.

Hatch, M. J. and Schultz, M. (2001), "Bringing the Corporation into Corporate Branding”, European Journal of Marketing, Vol. 37, No. 7/8, pp. 1041-1064.

Judge, A. 2002. Psychology of Sustainability: Embodying Cyclic Environmental Processes, UN World Summit on Sustainable Development (Johannesburg, 2002), http://www.laetusinpraesens.org/docs/psychsus.php.

Kanter, R. M. (2008), “Transforming Giants”, Harvard Business Review, Special Centennial Issue, January, pp. 43-52.

Ketola, T. (2008), “A Holistic Corporate Responsibility Model: Integrating Values, Discourses and Actions", Journal of Business Ethics, 80: 419-435.

Kilbourne, W. (2004), "Sustainable Communication and the Dominant Social Paradigm: Can They Be Integrated?" Marketing Theory, Vol. 4, No. 3, pp. 187-208.

Kilbourne, W. and Carlson, L. (2008), "The Dominant Social Paradigm, Consumption and Environmental Attitudes: Can Macromarketing Education Help?” Journal of Macromarketing, Vol. 28, No. 2, June, pp. 106-121. 
Kitching, R. (1983), Systems Ecology, University of Queensland Press, Australia.

Klein, N. (2000), No Logo, Flamingo, London.

Locke, J. (1980), Second Treatise of Government, Hackett, Cambridge, MA, USA.

Lovelock, J. (2000a), Gaia: A New Look at Life on Earth, Oxford University Press, Oxford.

Lovelock, J. (2000b), The Ages of Gaia: A Biography of Our Living Earth, Bantam, New York.

Lovelock, J. (2006), The Revenge of Gaia: Why the Earth is Fighting Back, Penguin Books, London.

Lovins, A. (2007), Forward to: Capitalism as it the World Matters, J. Porritt, Earthscan, London.

Marcuse, H. (1964), One Dimensional Man, Beacon Press, Boston, MA, USA.

McDonough, W. and Braungart, M. (2002a), Cradle to Cradle: Remaking the Way We Make Things, North Point Press, New York.

McDonough, W. and Braungart, M. (2002b), "Design for the Triple Top Line: New Tools for Sustainable Commerce", International Journal of Corporate Sustainability, Vol. 9, No. 3, pp. 251-258.

Naess, A. (1988), “The Basics of Deep Ecology”, Resurgence, January/February, pp. 47-62.

Naess, A. (1995), Self Realisation: An Ecological Approach To Being In The World, Murdoch University, USA.

Odum, E. (1994), Ecological and General Systems: An Introduction to Systems Ecology, University Press of Colorado, Niwot, Colorado, USA.

Parnell, J. (2008), “Sustainable Strategic Management: Constructs, Parameters, Research Directions”, International Journal of Sustainable Strategic Management, Vol. 1, No. 1, pp. 35-45.

Porritt, J. (2007), Capitalism As If the World Matters, Revised Edition, Earthscan, London. 
Porter, M. and van der Linde, C. (1995), "Green and Competitive: Ending the Stalemate", Harvard Business Review, September, Vol. 73, No. 5, pp. 120-134.

Porter, M. (2008), “The Five Competitive Forces That Shape Strategy”, Harvard Business Review, January, pp. 79-93.

Prahalad, C. K. and Hart, S. (2002), "The Fortune at the Bottom of the Pyramid", Strategy and Business, January, Vol. 26, pp. 54-67.

Schumacher, E. F. (1989), Small Is Beautiful: A Study of Economics as if People Mattered. Vintage, London.

Senge, P. (2006), The Fifth Discipline, Revised Edition, Currency, Australia.

Sessions, G. (Ed.) (1995), Deep Ecology for the Twenty-First Century, Shambhala, Boston, USA.

Sharma, S. and Vredenburg, H. (1998), "Proactive Corporate Environmental Strategy and the Development of Competitively Valuable Organisational Capabilities", Strategic Management Journal, August, Vol. 19, No. 8, pp. 729-753.

Sharma, S., Pablo, A. and Vredenburg, H. (1999), "Corporate Environmental Responsiveness Strategies", The Journal of Applied Behavioral Science, March, Vol. 35, No. 1, pp. 87-108.

Shrivastava, P. (1995), The Role of Corporations in Achieving Ecological Sustainability, The Academy of Management Review, October, Vol. 20, No. 4, pp. 936-960.

Skyttner, L. (2006), General Systems Theory: Problems, Perspective, Practice, World Scientific Publishing Company, Singapore.

Stead, W. E. and Stead, J. G. 2004. Sustainable Strategic Management, M. E. Sharpe Inc., New York.

Stead, J. G. and Stead, W. E. 2008. "Sustainable Strategic Management: An Evolutionary Perspective", International Journal of Sustainable Strategic Management, Vol. 1, No. 1, pp. $62-81$. 
Thomas, M. J. (2008), "Marketing as A Caring Profession”, in Kitchen, P. J. (2008), Marketing, Metaphors and Metamorphosis, Palgrave Macmillan, UK.

Viswanathan, N. and Dickson, P. (2007), "The Fundamentals of Standardising Global Marketing Strategy", International Marketing Review, Vol. 24, No. 1, pp. 46-63.

Willard, B. (2002), The Sustainability Advantage, New Society, Gabriola Island, British Columbia, Canada. 


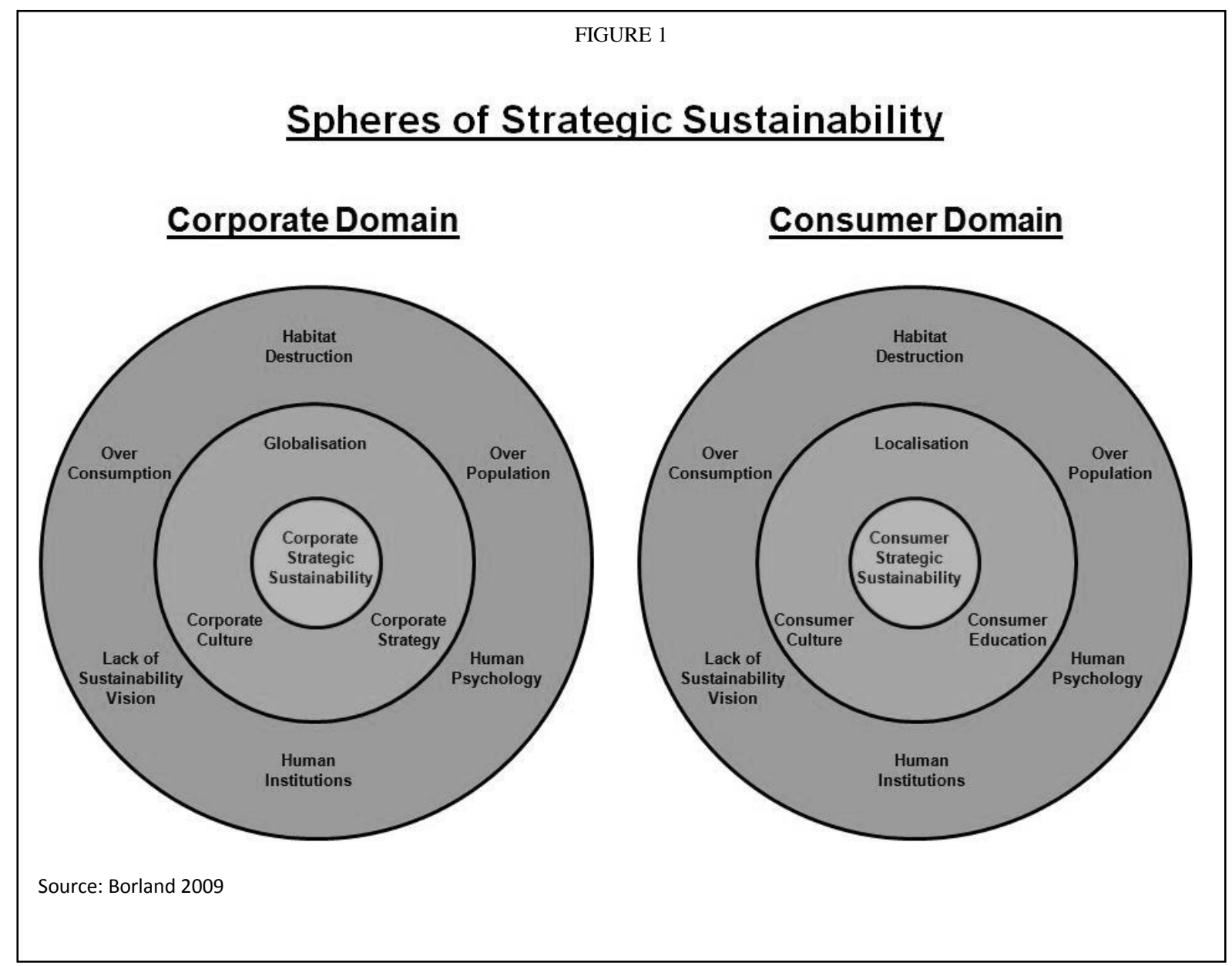




\section{Quadruple Top Line}

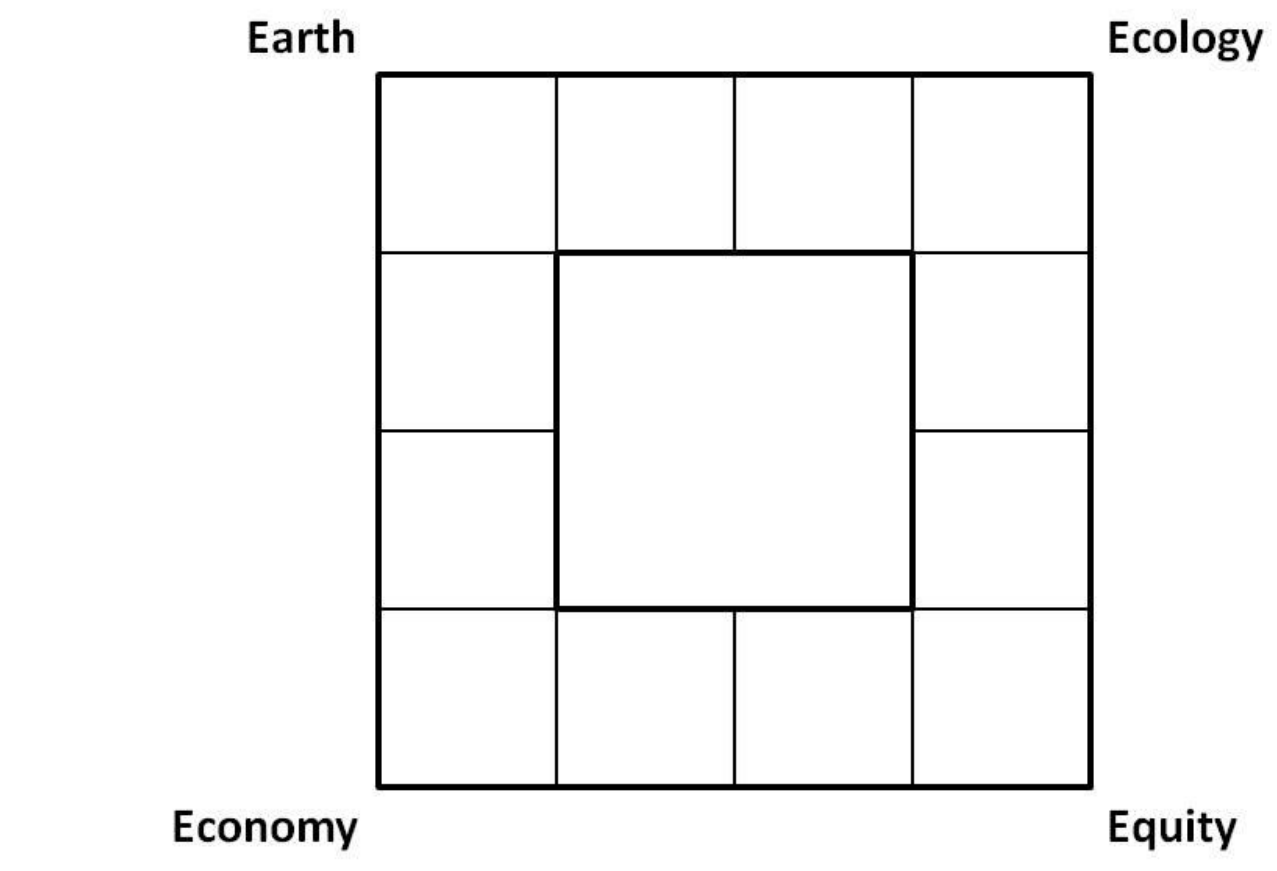

FIGURE 3

Strategic Sustainability Hierarchy

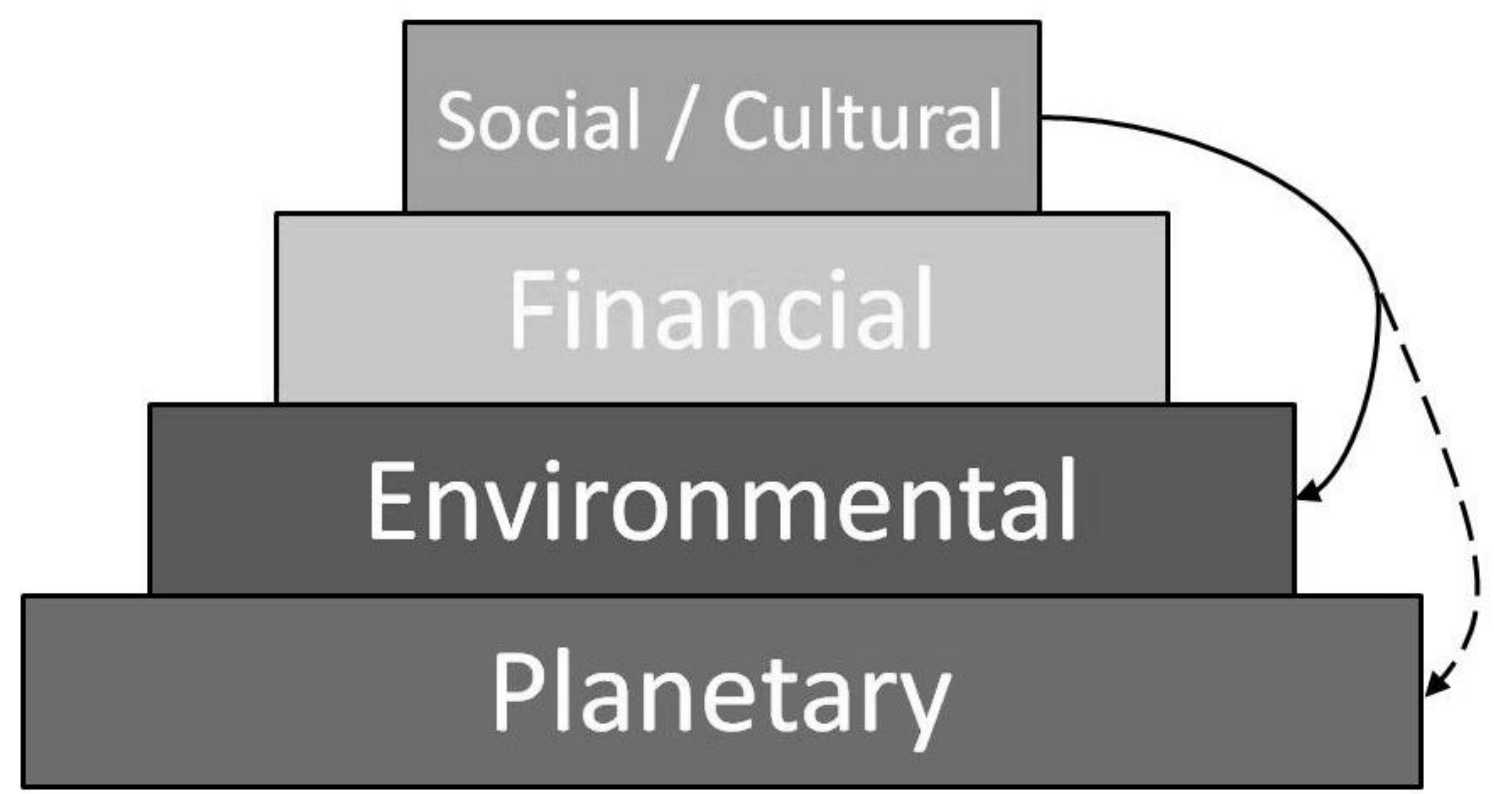

Source: Borland 2009 